\title{
Use of an innovative T-tube maze assay and the proboscis extension response assay to assess sublethal effects of GM products and pesticides on learning capacity of the honey bee Apis mellifera $\mathbf{L}$.
}

\author{
Peng Han · Chang-Ying Niu $\cdot$ Chao-Liang Lei $\cdot$ \\ Jin-Jie Cui $\cdot$ Nicolas Desneux
}

Accepted: 10 September 2010/Published online: 26 September 2010

(C) The Author(s) 2010. This article is published with open access at Springerlink.com

\begin{abstract}
Transgenic Cry1Ac+CpTI cotton (CCRI41) is a promising cotton cultivar throughout China but side effects and especially sublethal effects of this transgenic cultivar on beneficial insects remain poorly studied. More specifically potential sublethal effects on behavioural traits of the honey bee Apis mellifera L. have not been formally assessed despite the importance of honey bees for pollination. The goal of our study was to assess potential effects of CCRI41 cotton pollen on visual and olfactory learning by honey bees. After a 7-day oral chronic exposure to honey mixed with either CCRI41 pollen, imidaclopridtreated conventional pollen (used as positive sublethal control) or conventional pollen (control), learning performance was evaluated by the classical proboscis extension reflex (PER) procedure as well as a T-tube maze test. The latter assay was designed as a new device to assess potential side effects of pesticides on visual associative learning of honey bees. These two procedures were complementary because the former focused on olfactory learning while the latter was involved in visual learning based on visual orientation ability. Oral exposure to
\end{abstract}

P. Han · C.-Y. Niu $(\bowtie) \cdot$ C.-L. Lei

College of Plant Science \& Technology, Hubei Key Laboratory of Utilization of Insect Resources and Sustainable Control of Pests, Huazhong Agricultural University, Shizi Mountain Road, Wuhan 430070, China

e-mail: niuchy2004@yahoo.com.cn

J.-J. Cui

Institute of Cotton Research, Chinese Academy of Agricultural

Sciences, Huanghe Road, Anyang, China

N. Desneux

Unité de Recherches Intégrées en Horticulture, French National Institute for Agricultural Research (INRA), 400 Route des chappes, Sophia-Antipolis, France
CCRI41 pollen did not affect learning capacities of honey bees in both the T-tube maze and PER tests. However, exposure to imidacloprid resulted in reduced visual learning capacities in T-tube maze evaluation and decreased olfactory learning performances measured with PER. The implications of these results are discussed in terms of risks of transgenic CCRI41 cotton crops for honey bees.

Keywords Sublethal effect · Proboscis extension response $\cdot$ Visual learning ability $\cdot$ T-tube maze $\cdot$ Cry1 Ac . CpTI $\cdot$ Cotton $\cdot$ Pollen $\cdot$ Imidacloprid

\section{Introduction}

In China, genetically modified (GM) cotton covers $70 \%$ of the total cotton planting areas (Stone 2008). Transgenic Cry1Ac (Bt toxin)+CpTI (Cowpea trypsin inhibitor) cotton cultivar CCRI41 is widely used in China (50\% of total cotton crops) because it reduces pest damages and delays the development of resistance in pest insects (Cui 2003; Gassmann et al. 2009). Cry1Ac is considered a Lepidopteran-specific toxin (Höfte and Whiteley 1989) and CpTI affects metabolic processes of Lepidopteran and Coleopteran insects (Boulter et al. 1989). CCRI41 is primarily cultivated in the Yellow river cotton (YRC) zone where it covers over 5.2 million hectares (http://www. agri.gov.cn).

Honey bees, Apis mellifera L. account for at least $80 \%$ of total pollinating insects of major crops (Klein et al. 2007) and are the most important pollinators in the YRC area. Pollen is a major food for young bees (Haydak 1970) and bee foragers collect large amounts of nectar and pollen from cotton plants, including pollen of transgenic CCRI41 cotton. Entire colonies could be exposed to Cry1Ac and 
CpTI toxins. Although laboratory studies have shown no lethal effect of Cry1Ac+CpTI cotton pollen on bees (Liu et al. 2009; Han et al. 2010), the potential sublethal effects of Cry1Ac+CpTI toxins on honey bees need to be assessed, since side effects of another Bt toxin (Cry1Ab) on bee learning capacities and overall foraging activity have been already reported (Ramirez-Romero et al. 2005, 2008). Risk assessment for GM crops on pollinators may be an important issue (Andow and Zwahlen 2006; Desneux and Bernal 2010), notably because of global decline of bees worldwide (Oldroyd 2007; Stokstad 2007).

Development of physiological processes involved in olfaction and learning performance takes place during the period that larvae and young adult honey bees feed on pollen (Masson and Arnold 1984; Masson et al. 1993). Learning performance is of primary importance in honey bees when they become foragers (Seeley 1985; Menzel 1993; Hammer and Menzel 1995). Because the food sources (blooming plant species) change every few days, bees acquire and store reward-related information by way of associative learning between the food resource and olfactory and colour information (Behrends and Scheiner 2009; Srinivasan 2010). Behavioural plasticity is crucial for exploitation of food resources because it allows foraging honey bees to move from depleted flowers to new ones swiftly (Herrera 1990). Any decrease in visual or olfactory learning capacities could lead to reduced foraging efficiency and induce a general decline in bee hive populations (Desneux et al. 2007; Decourtye et al. 2010).

Conditioned proboscis extension response (PER) is a standard procedure to assess the sublethal effect of neurotoxic pesticides on olfactory learning of honey bees (Abramson et al. 1999; Decourtye and Pham-Delègue 2002; Decourtye et al. 2003, 2004; Desneux et al. 2007). This assay has also been used to demonstrate side effects of toxins from GM crops on honey bee learning (Picard-Nizou et al. 1997; Pham-Delègue et al. 2000; Ramirez-Romero et al. 2008). During conditioning, the PER is elicited by contacting the gustatory receptors of the antennae with a sucrose solution (unconditioned stimulus), and simultaneously delivering an odour (conditioned stimulus). Bees can exhibit the PER as a conditioned response to the odour alone after even a single pairing of the odour with a sucrose reward.

Accurate assessment of sublethal effects of toxic products (like pesticides or toxins from GM crops) on bee visual learning capacity may be achieved using labyrinth or maze assays (Desneux et al. 2007; Decourtye et al. 2009). Honey bees could discriminate blue colour among other colours and they could obtain a reward placed on a piece of blue cardboard surrounded by cards of other colours (Von Frisch 1915; Srinivasan 2010). In a complex labyrinth, bees could learn to navigate through mazes by using colour cues and marks to trace novel paths through the maze (Zhang et al. 1996, 2000). Orientation performance of bees in a maze relies on associative learning between a visual mark and a reward of sugar solution (Zhang et al. 1996) in a similar way as in the PER test. The two assays thus appear complementary encompassing main potential disturbances of learning capacities of bees.

In this context, the aim of our study was to provide a sublethal toxicity assessment of transgenic CCRI41 pollen on the honey bee, A. mellifera by evaluating two aspects of learning performance after chronic oral exposure: (i) visual learning abilities based on visual orientation by developing and using an innovative T-tube maze assay, and (ii) olfactory learning capacities measured with a classical PER procedure. Based on previous work demonstrating highly variable expression level of Cry1Ac in cotton pollen throughout the season (Han et al. 2010), we used cotton pollen containing the highest concentration (worst case exposure scenario) to conduct our experiments. The pesticide imidacloprid (neonicotinoid) at $48 \mathrm{ppb}$ (part per billion) was used as positive sublethal control because of its deleterious effects on learning performance in honey bees in PER assays (Decourtye et al. 2003; RamirezRomero et al. 2008; Han et al. 2010). In addition, potential deleterious effect of sublethal doses of imidacloprid on bee visual learning capacity still needed to be assessed.

\section{Materials and methods}

\section{Cotton varieties}

Transgenic Cry1Ac+CpTI cotton cultivar CCRI41 and its untransformed parent cultivar CCRI23 were provided by the Institute of Cotton Research, Chinese Academy of Agricultural Sciences. Both cultivars were planted in early May 2009 in experimental fields of Huazhong Agricultural University and routine management was conducted except for pesticide application. Pollen samples were collected on the 20th of June, July, and August, which referred to cotton early bloom, mid-stage bloom and late bloom respectively. These pollens were then stored at $-80^{\circ} \mathrm{C}$ for later experiments. Such freezing process did not impact stability and activity of the Cry1Ac and CpTI toxins (Liu et al. 2009; Han et al. 2010).

\section{Chronic oral exposure}

Conventional cotton pollen, CCRI41 cotton pollen collected in July (i.e. the worst case scenario because it containing the highest amount of Cry1Ac toxin [300 $\left.\pm 4.52 \mathrm{ng} \mathrm{g}^{-1}\right]$, see Han et al. 2010) and imidacloprid-treated conventional cotton pollen were used in the experiments as three different 
treatments. The preparation of treated pollen followed methods reported previously (Han et al. 2010). Three different diets were prepared by mixing water, honey and pollens at the rates of 1:2:7 (weight) and the positive sublethal control (imidacloprid-treated pollen) contained the imidacloprid at a concentration of $48 \mathrm{ng} \mathrm{g}^{-1}$ (48 ppb). This concentration of imidacloprid was chosen accordingly to the work by Ramirez-Romero et al. (2008) and was validated as a sublethal concentration (as defined by Desneux et al. 2007, a concentration defined as inducing no statistically significant mortality in the experimental population) in our exposure conditions in a companion study (Han et al. 2010).

Emerging honey bees were collected from a bee colony during summer. Bees were placed in groups of 40 individuals in glass-made cages $(15 \times 10.5 \times 20 \mathrm{~cm})$ adapted from the Pain cage (Pain 1966) with the top covered with a piece of mesh to ensure effective ventilation. A $10 \mathrm{ml}$ centrifuge tube was inserted in each cage containing foods for honey bees. The cages were kept in an incubator in the dark at $33 \pm 1{ }^{\circ} \mathrm{C}$ and $55 \pm 5 \% \mathrm{RH}$. Sucrose solution, honey and conventional pollen were provided for the bees in the first 2 days to adapt to the experimental conditions. Subsequently, the bees were exposed to the three different dietary treatments for 7 days (Han et al. 2010) and then the surviving bees were prepared for T-tube maze evaluation and the PER test when they become foragers at approximately 12 days old (young adult bees were collected at 1 day after emergence, 2 days for adapting period, 7 days dietary treatment, 1 day of starvation before the T-maze conditioning and 1 day for T-tube experiment) (Seeley 1983). Four replicates were undertaken per treatment, with 40 honey bees tested per replicate (all replicates undergone simultaneously).

T-tube maze assay

A T-tube maze assembled of two glass T-tubes was designed to assess visual learning capacity of honey bees. It was designed to be simpler to operate than the complex maze developed by Zhang et al. (1996). Each T-tube had two arms of $12 \mathrm{~cm}$ length each and an entry section of $20 \mathrm{~cm}$ length (internal diameter: $1.6 \mathrm{~cm}$ ) (Fig. 1a). Two arms were completely covered with yellow or blue ray filter papers to provide different colour stimuli (conditioned stimulus). Yellow and blue colours were chosen to conduct the T-tube assay because these colours are spectrally separated for bees (Zhang et al. 1996) and also because a previous study showed that other bees (bumble bees) are less accurate at discriminating spectrally close colours (Chittka et al. 2003). In addition, Zhang et al. (1996) reported an innate preference for the yellow colour in landing honey bees and in a pilot experiment we found an innate (I) preference of bees for yellow versus

\section{A T-tube}
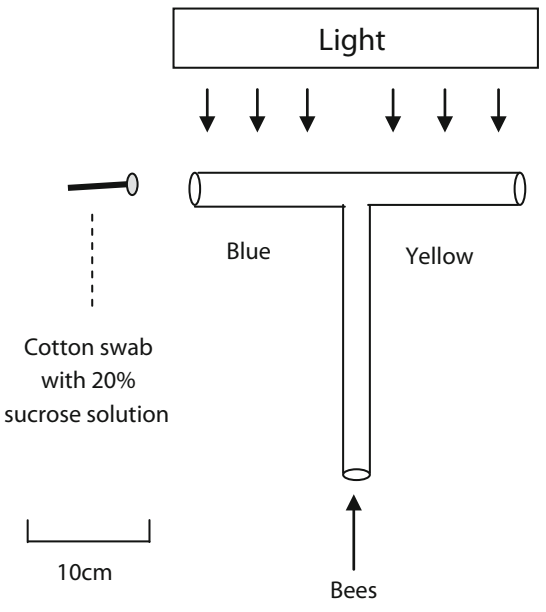

B T-tube maze

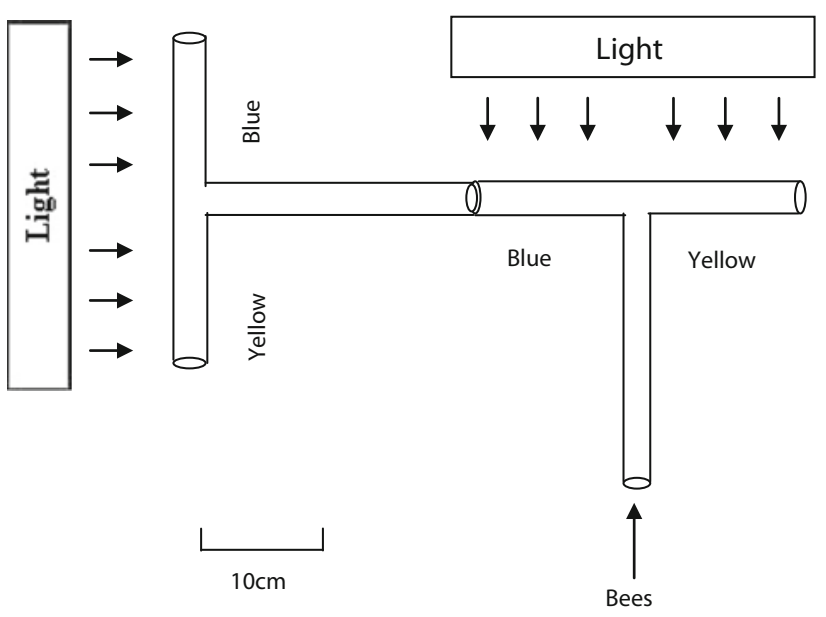

Fig. 1 a The single T-tube used for the conditioning sessions $(\mathrm{C} 1$, C2, C3): cotton swab with $20 \%$ sucrose was used as a reward (unconditioned stimulus) at the end of the blue coloured arm (conditioned stimulus). These two stimuli were used together to establish CS/US association in honey bees (i.e. associate learning for blue colour). b The assembled T-tube maze used in the evaluation session (E): this device was used to test whether the bees could successfully negotiate to the last blue section through the maze after the conditioning sessions

blue ( $73 \%, n=159$ bees). Thus we used the blue colour (vs. yellow) as visual cue for conditioning because learning a non-preferential colour ensured an effective measure of bee visual learning capacity.

The honey bees were starved for $24 \mathrm{~h}$ before conditioning. During conditioning trials, the honey bees were placed in the entry section individually and a reward consisting of a cotton swab with $20 \%$ sucrose was placed at the end of the blue arm (Fig. 1a). Three conditioning sessions were then carried out at 20 min intervals $(\mathrm{C} 1, \mathrm{C} 2, \mathrm{C} 3)$, and preference results in $\mathrm{C} 2$ and $\mathrm{C} 3$ were recorded because there was no associative learning experience before bees 
went through the $\mathrm{C} 1$ (thus $\mathrm{C} 1$ served as initial conditioning session). The number of individuals succeeding in negotiating the T-tube to get the reward at the end of the blue arm was recorded whereas the individuals initially failing to go to blue session were blocked at the end of the yellow arm until they crawled back to get the reward in the blue arm. In order to avoid potential pheromone interference between individuals, the tube was washed with ethanol and dried before the next bee was prepared for conditioning.

At the end of the three conditioning sessions, the honey bees were then subjected to an evaluation session (E). To this end, two single T-tubes were assembled to form a T-tube maze (Fig. 1b) to test whether the bees could negotiate the maze and reach the last blue section of the maze successfully.

In order to avoid unintended bias in honey bees during the assays, the colours were exchanged between the different arms of the T-tube and T-tube maze for each new conditioning session. Indeed, Zhang et al. (2000) showed that a constant turn, for example in a maze where the goal is reached by always making a left turn, was more easily learned by bees. In the same line of reasoning, during T-tube maze evaluation session we assembled the maze in an opposite manner which means the bees were able to find the reward (choose 2 times the blue arms in the T-tube maze) only when they turn left first and then turn right.

\section{Conditioned proboscis extension reflex assay}

Olfactory-conditioned PER has been established as a classical procedure for evaluating the olfactory learning in honey bees (Pham-Delègue et al. 1993; Decourtye et al. 2003, 2004; Ramirez-Romero et al. 2005, 2008; Desneux et al. 2007). After finishing the T-tube maze assay when the honey bees were about 13-days old, the bees were trapped individually in a cut off pipette tip with only their antennae and mouthparts free. Bees were starved for $3 \mathrm{~h}$ prior to conditioning and then placed in the main airflow $(50 \mathrm{ml} / \mathrm{s})$ to be familiarized with the experimental context. For the conditioning trials, linalool, a common floral odour (Blight et al. 1997) (10 $\mu \mathrm{l}, 98 \%$ purity, Aladdin, Shanghai) was used as the conditioned stimulus. It was deposited on a filter paper strip inserted in a Pasteur pipette cartridge and was delivered through a secondary airflow $(2.5 \mathrm{ml} / \mathrm{s}$ for 6s). During odour delivery, the PER was elicited after $3 \mathrm{~s}$ by contacting the antennae with a sucrose solution (30\%) as the unconditioned stimulus, and the same solution was immediately given as a reward, before the odour delivery ended. Three conditioning sessions were carried out at 20 min intervals (conditioning phase; $\mathrm{C} 1, \mathrm{C} 2$ and $\mathrm{C} 3$ ). The individuals were then subjected to five test (extinction) trials (E1-E5), during which the conditioned stimulus (linalool) was delivered for $6 \mathrm{~s}$ at $20 \mathrm{~min}$ intervals, without the unconditioned stimulus and the reward. The conditioned PER was recorded as a yes-or-no response during the test sessions.

\section{Statistical analysis}

Proportions of CCRI41-exposed and imidacloprid-exposed bees succeeding in $\mathrm{T}$-tube and $\mathrm{T}$-tube maze trails during the conditioning ( $\mathrm{C} 2$ and $\mathrm{C} 3$ ) sessions and the evaluation session (E) were compared to the proportions observed in the control group using permuted Fisher's exact tests (proc multtest). Similar statistical analyses were used to compare responses of CCRI41-exposed and imidacloprid-exposed bees to responses from control bees during PER conditioning and extinction sessions. All statistical analyses were performed using SAS Version 8.0 (SAS Institute Inc., Cary, USA).

\section{Results}

Visual learning capacity in T-tube maze assay

The results (Fig. 2) showed that the proportion of imidacloprid-exposed bees that successfully navigated through the single T-tube in third conditioning session (C3: $P=0.018)$ and evaluation session in the T-tube maze (E: $P<0.001)$ were significantly lower than those from control group. However, the capacity of honey bees fed on

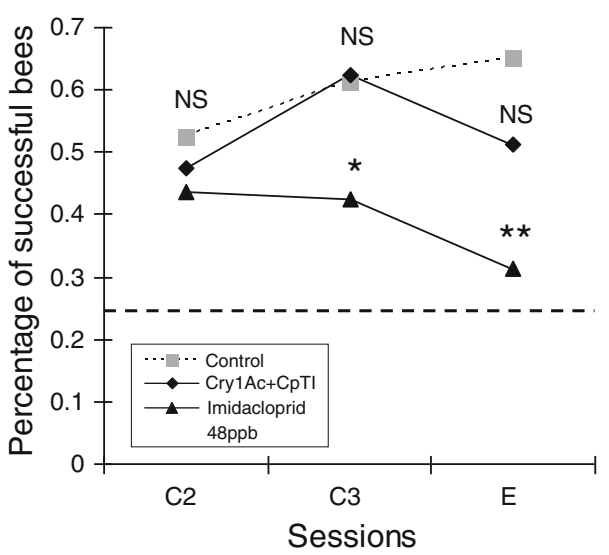

Fig. 2 Percentage of individuals ( $n=80$ bees tested per group) (a sub-sample of surviving active bees selected for this test, $n=20,4$ replicates) succeeding in navigating the single T-tube and assembled T-tube maze to obtain the reward at the end of the blue arm after a 7-day period of oral exposure to food containing conventional pollen (control), Cry1 Ac+CpTI pollen, or imidacloprid-contaminated (48 ppb) conventional pollen. Dashed line indicates innate response of bees to the blue colour. Session C2, C3 and E refer to the second and third conditioning sessions and the evaluation session respectively. A permuted Fisher exact test was used to compare treatments, $* P<0.05, * * P<0.01, \quad N S$ not significant (when no treatments differed from the control for a given trial, NS is reported only once) 
CCRI41 pollens were not significantly affected in the two conditioning sessions (C2: $P=0.329 ; \mathrm{C} 3: P=0.459)$ and T-tube maze evaluation session $(\mathrm{E}: P=0.338)$ compared with control-bees.

In general, the percentage of successful individuals increased gradually from about $27 \%$ (innate response to blue colour) to approximately $50-60 \%$ in C2 and C3 sessions (except for the imidacloprid group), which indicated a good visual learning ability and orientation plasticity in honey bees from CCRI41 and control groups.

Olfactory learning capacity: proboscis extension reflex

The percentage of individuals showing an initial PER response in Cry1Ac+CpTI treatment $(90 \%)$ and in imidacloprid $(85 \%)$ were not significantly different from those recorded in control group $(87.5 \%)$, which indicated that the exposure did not affect the state of sensor-motor pathway underlying the PER (Ramirez-Romero et al. 2008).

During PER, the honey bees fed on CCRI41 pollens were not significantly affected during the whole conditioning process and extinction process (all $P>0.05$; Fig. 3). However for the imidacloprid group, a significant difference was observed in $\mathrm{C} 3(P<0.001)$, E2 $(P=$ $0.019), \mathrm{E} 3(P=0.007)$ and E5 $(P=0.040)$ compared to control bees.

\section{Discussion}

Focusing on learning performance in our study, the results suggested that CCRI41 cotton pollen has no negative effects on honey bees that were exposed for 7 days during the early adult stage. The proportion of CCRI41-exposed bees responding to blue colour in single T-tube conditioning and assembled T-tube maze evaluation was not reduced significantly compared to the control group. In addition, honey bees performed equally well as control bees in the PER bioassay and no significant behavioural modification was induced by CCRI41 cotton pollen exposure. In contrast, the sublethal dose of imidacloprid decreased both visual and olfactory learning capacities. For the first time we demonstrate that a sublethal dose of a neonicotinoid insecticide, imidacloprid, could reduce visual learning capacity in honey bees. Our study is also the first to evaluate potential sublethal effects of a transgenic Cry1Ac+CpTI cotton cultivar on two aspects of learning in honey bees simultaneously and to use a newlydesigned T-tube maze procedure to address risk assessment of GM crops.

\section{Sublethal effects on learning}

Stimulus acquisition and discrimination, and learning are complex processes which largely contribute to colony health and social lifestyle in honey bees (Srinivasan 2010). These processes crucial for foraging activities are very important to bee colonies because of their logistic function providing all individuals with food. However, they could be impaired by agricultural synthetic pesticides (for review see Desneux et al. 2007), and potentially also by insecticidal proteins expressed in GM crops (Ramirez-Romero et al. 2008). It suggests the importance of assessing these potential behavioural impacts using accurate bioassays. Our study proposes using PER and T-tube maze bioassays to measure negative impacts of these products on honey bees.

Only about $40 \%$ of honey bees from the imidacloprid treatment made the correct decision to get the reward in the
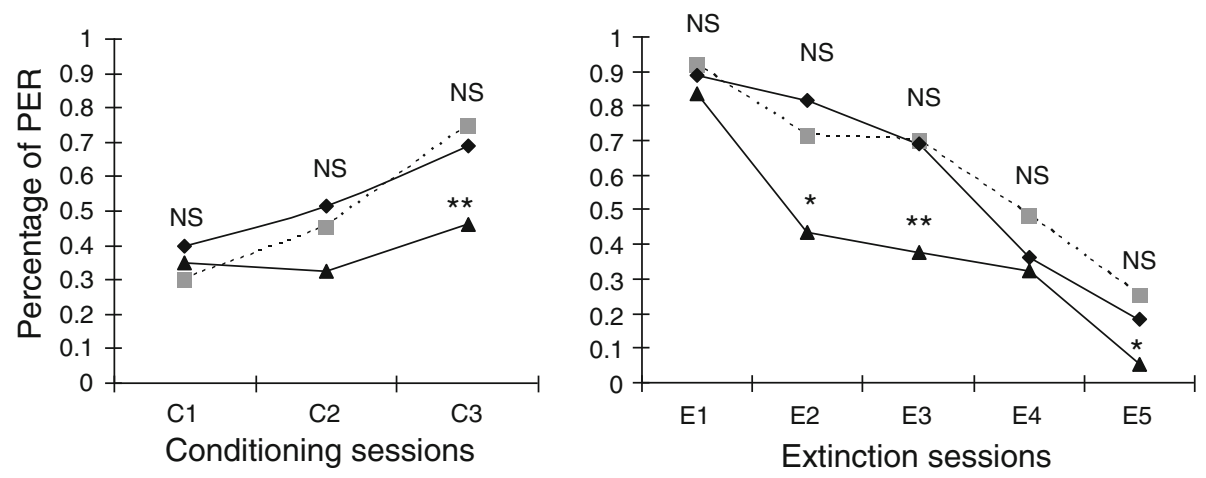

$\cdots \cdot \cdot \cdot$ Control $\longrightarrow$ Cry1 AC+CpTI $\longrightarrow$ Imidacloprid 48ppb

Fig. 3 Percentage of honey bees $(n=80$ bees tested per group) showing a PER (a sub-sample of surviving active bees selected for showing a PER before the conditioning, $n=20,4$ replicates) during conditioning trails $(\mathrm{C} 1-\mathrm{C} 3)$ and extinction trails (E1-E5 after a 7-day period of oral exposure to food containing conventional pollen (control), Cry1Ac+CpTI pollen, or imidacloprid-contaminated
(48 ppb) conventional pollen. A permuted Fisher exact test was used to compare treatments, $* P<0.05$, $* * P<0.01$ indicated a significant difference with the control, NS not significant (when no treatments differed from the control for a given trial, NS is reported only once) 
third conditioning session (C3) of the T-tube test, indicating that their visual learning ability based on visual orientation may be lower than that of bees from CCRI41 and control groups. Furthermore, this difference increased compared with the control group in the T-tube maze evaluation session (E). During this session, the performance of CCRI41-exposed bees slightly decreased to a relatively low level at $50 \%$, but was not significantly different from the control group. Together, these results suggest that the visual learning ability based on visual orientation was not significantly affected in honey bees fed CCRI41 cotton pollen but honey bees exposed to imidacloprid-treated pollen were perturbed. Recently, El Hassani et al. (2005) and Decourtye et al. (2009) reported that orientation capacity in honey bees declined dramatically when exposed to the pesticide fipronil, though only the last study also assessed visual learning activity. Bees can perceive visual information easily and accurately (Srinivasan 2010), but memory-formation based on associative learning appears to be more complicated. Our new T-tube maze assay integrating visual information and spatial orientation has proved useful to evaluate visual learning plasticity. Presumably, imidacloprid may have a physiological effect on visual information storage and memory consolidation of bees (Desneux et al. 2007) and under natural conditions this side effect may lead to lower foraging efficiency or orientation loss in exposed bees. We demonstrate a new means by which neonicotinoid pesticides may induce unexpected decrease in honey bee foraging efficiency, which might be linked to the honey bees worldwide decline (Stokstad 2007) and also to the colony collapse disorder syndrome (vanEngelsdorp and Meixner 2010). Careful attention should be paid on these potential subtler behavioural effects on honey bees.

Regarding the PER procedure, conditioning resulted in the establishment of the conditioned stimulus/unconditioned stimulus association (Decourtye et al. 2003), and the extinction process indicated the plasticity of PER response, which has been shown to be directly related to foraging efficiency (Ramirez-Romero et al. 2005). Also, it was reported that the results from PER are consistent with those obtained under semi-field conditions after bees were exposed to pesticides (Decourtye et al. 2004), suggesting that results of the PER procedure are ecologically meaningful. In the imidacloprid-exposed bees, a significantly lower percentage of individuals showing a PER response were observed in C3, E2, E3 and E5, which indicates that imidacloprid indeed impacted honey bees both in conditioning and extinction processes. These effects were consistent with those reported by Decourtye et al. (2003) and Ramirez-Romero et al. (2008) and highlighted the potential of this insecticide to affect multiple behavioural and learning processes as demonstrated in other studies
(Decourtye et al. 2001, 2003, 2004; Guez et al. 2001; Lambin et al. 2001; Ramirez-Romero et al. 2005; Desneux et al. 2007; Yang et al. 2008). In contrast, CCRI41 cotton pollen exposure did not induce any learning behaviour modification in honey bees suggesting that the bees were able to learn the conditioned stimulus accurately and showed a normal behavioural plasticity.

Implications for risk assessment

Our results show that CCRI41 pollen impose no risk on learning performance, suggesting that the efficiency of exposed bees in YRC when visiting flowers and foraging nectars is not affected. The supply of food resources for the whole beehive would not be impaired by consumption of Cry1Ac+CpTI cotton pollen in this region. In contrast, imidacloprid-contaminated food induced a reduction in visual learning capacities, which may lead to reduced foraging efficiency and disorientation in honey bees (Menzel 1993; Desneux et al. 2007). It should be stressed that multiple sublethal effects of imidacloprid were reported on behavioural and foraging performances of honey bees when exposed at realistic (Bonmatin et al. 2005) lower doses (6 ppb: Colin et al. 2001; 4 ppb: Decourtye et al. 2001) than the one tested in our study (48 ppb). Thus, it is likely that the LOEC (lowest observed effect concentration) of imidacloprid for visual learning and orientation in honey bees is much lower than $48 \mathrm{ppb}$. Such ecologically deleterious effects on honey bees of this systemic pesticide (usually used as seed dressing), and potential negative effects on other non-target insects in cotton agro-ecosystems, deserve more attention (Desneux et al. 2007).

We propose that the T-tube maze procedure as a useful bioassay for assessing the sublethal effects of pesticides or GM products on visual learning by honey bees (and potentially by other non-target organisms). Still, more work is needed to verify the reliability and practical meaning of this procedure. The potential risk assessment posed by GM crops on pollinators and other beneficial arthropods mainly depends on case-by-case analysis (Malone and PhamDelègue 2001) though extensive efforts have been done to adapt the tiered approach that is used internationally within chemical pesticides regulatory for the risk assessment of the GM crops to non-target arthropods (Romeis et al. 2008). It is essential to develop reliable tools for measuring precisely potential physiological and behavioural disturbances in exposed non-target organisms (Lovei and Arpaia 2005; Ramirez-Romero et al. 2005, 2008; Chen et al. 2010; Desneux et al. 2010; Mommaerts et al. 2010).

Our results provide important information on potential threats to honey bees posed by insecticidal toxins and pesticide, and more specifically how these products may (or may not) affect learning and foraging efficiency of honey 
bees. However it should be pointed that further investigations under more natural conditions would ideally complete our assessment because of the uncertainty of external factors, such as pesticide residual level (Desneux et al. 2007) and other complex behavioural and physiological traits implicated in honey bee colony health (Masson and Arnold 1984; Greggers and Menzel 1993; Behrends and Scheiner 2009; Srinivasan 2010). The study of the two crucial aspects of learning presented here can be ecologically meaningful regarding honey bee conservation and future works should focus on validating the ecological meaning of the results. The two evaluation tools T-tube maze and PER can be used in a complementary manner, allowing an assessment of both visual and olfactory learning capacities (provided consistent results in our study).

In this instance, the results showed no sublethal effect on learning performance in honey bees after oral exposure to CCRI41 pollen. Because exposure levels to Cry1Ac and CpTI proteins used in our study are consistent between laboratory experiments and natural conditions (Han et al. 2010), we conclude that sublethal effects of CCRI41 pollen on learning performance of honey bees is unlikely in natural conditions.

Acknowledgments We thank Dr Ronald F.L. Mau and Dr. Jetske deBoer for comments on earlier versions of the manuscript. This study was supported by the project "Risk assessment of GM crops on Non-target Organisms" grants from Institute of Cotton Research, Chinese Academy of Agricultural Sciences.

Open Access This article is distributed under the terms of the Creative Commons Attribution Noncommercial License which permits any noncommercial use, distribution, and reproduction in any medium, provided the original author(s) and source are credited.

\section{References}

Abramson CI, Aquino IS, Ramalho FS, Price JM (1999) The effect of insecticides on learning in the Africanized honey bee (Apis mellifera L.). Arch Environ Contam Toxicol 37:529-535

Andow DA, Zwahlen C (2006) Assessing environmental risks of transgenic plants. Ecol Lett 9:196-214

Behrends A, Scheiner R (2009) Evidence for associative learning in newly emerged honey bees (Apis mellifera L.). Anim Cogn 12:249-255

Blight MM, Le Metayer M, Pham-Delègue MH, Pickett John A, Marion-Poll F, Wadhams LJ (1997) Identification of floral volatiles involved in recognition of oilseed rape flowers, Brassica napus by honeybees, Apis mellifera. J Chem Ecol 23:1715-1727

Bonmatin JM, Moineau I, Charvet R, Colin ME, Fleche C, Bengsch ER (2005) Behaviour of imidacloprid in fields. In: Lichtfouse E, Schwarzbauer J, Robert D (eds) Environmental chemistry: green chemistry and pollutants in ecosystems. Springer, Berlin, pp 483-494

Boulter D, Gatehouse AMR, Hilder V (1989) Use of cowpea trypsininhibitor $(\mathrm{CpTI})$ to protect plants against insect predation. Biotechnol Adv 7:489-497
Chen LZ, Cui JJ, Ma WH, Niu CY, Lei CL (2010) Pollen from Cry1Ac/ CpTI-transgenic cotton does not affect the pollinating beetle Haptoncus luteolus. J Pest Sci. doi:10.1007/s10340-010-0319-0

Chittka L, Dyer AG, Bock F, Dornhaus A (2003) Bees trade off foraging speed for accuracy. Nature 424:388

Colin ME, Le Conte Y, Vermandere JP (2001) Managing nuclei in insect-proof tunnel as an observation tool for foraging bees. In: Belzunces LP, Pelissier C, Lewis GB (eds) Hazards of pesticides to bees. INRA, Paris, pp 259-268

Cui JJ (2003) Effects and mechanisms of the transgenic Cry1Ac plus CpTI (cowpea trypsin inhibitor) cotton on insect communities. $\mathrm{PhD}$ Dissertation. Chinese Academy of Agricultural Sciences, $\mathrm{p} 2$

Decourtye A, Pham-Delègue MH (2002) The proboscis extension response. Assessing the sublethal effects of pesticides on the honey bee. In: Devillers J, Pham-Delègue MH (eds) Honey bees: estimating the environmental impact of chemicals. Taylor \& Francis, New York, pp 67-81

Decourtye A, Le Metayer M, Pottiau H, Tisseur M, Odoux JF, Pham-Delegue MH (2001) Impairment of olfactory learning performances in the honey bee after long term ingestion of imidacloprid. In: Belzunces LP, Pelissier C, Lewis GB (eds) Hazards of pesticides to bees. INRA, Paris, pp 259-268

Decourtye A, Lacassie E, Pham-Delègue MH (2003) Learning performances of honeybees (Apis mellifera L.) are differentially affected by imidacloprid according to the season. Pest Manage Sci 59:269-278

Decourtye A, Devillers J, Cluzeau S, Charreton M, Pham-Delègue $\mathrm{MH}$ (2004) Effects of imidacloprid and deltamethrin on associative learning in honeybee under semi-field and laboratory conditions. Ecotox Environ Safe 57:410-419

Decourtye A, Lefort S, Devillers J, Gauthier M, Aupinel P, Tisseur M (2009) Sublethal effects of fipronil on the ability of honeybees (Apis mellifera L.) to orientate in a complex maze. In: Oomen PA, Thompson HM (eds) Hazards of pesticides to bees. Arno Brynda GmbH, Berlin, pp 75-83

Decourtye A, Mader E, Desneux N (2010) Landscape scale enhancement of floral resources for honey bees in agro-ecosystems. Apidologie 41:264-277

Desneux N, Bernal JS (2010) Genetically modified crops deserve greater ecotoxicological scrutiny. Ecotoxicology. doi:10.1007/ s10646-010-0550-8

Desneux N, Decourtye A, Delpuech JM (2007) The sublethal effects of pesticides on beneficial arthropods. Annu Rev Entomol 52:81-106

Desneux N, Ramirez-Romero R, Bokonon-Ganta AH, Bernal JS (2010). Attraction of the parasitoid Cotesia marginiventris to host frass is affected by transgenic maize. Ecotoxicology. doi: 10.1007/s10646-010-0502-3

El Hassani AK, Dacher M, Gauthier M, Armengaud C (2005) Effects of sublethal doses of fipronil on the behavior of the honeybee (Apis mellifera). Pharmacol Biochem Behav 82:30-39

Gassmann AJ, Carriere Y, Tabashnik BE (2009) Fitness costs of insect resistance to Bacillus thuringiensis. Annu Rev Entomol 54:147-163

Greggers U, Menzel R (1993) Memory dynamics and foraging strategies of honeybees. Behav Ecol Sociobiol 32:17-29

Guez D, Suchail S, Gauthier M, Maleszka R, Belzunces LP (2001) Contrasting effects of imidacloprid on habituation in 7- and 8-day-old honeybees (Apis mellifera). Neurobiol Learn Mem 76:183-191

Hammer TJ, Menzel R (1995) Learning and memory in the honeybee. J Neurosci 15:1617-1630

Han P, Niu CY, Lei CL, Cui JJ, Desneux N (2010) Quantification of toxins in a Cry1 Ac+CpTI cotton cultivar and its potential effects on the honey bee Apis mellifera L. Ecotoxicology doi:10.1007/ s10646-010-0530-z 
Haydak MH (1970) Honey bee nutrition. Annu Rev Entomol 15: $143-156$

Herrera CM (1990) Daily patterns of pollinator activity, differential pollinating effectiveness, and floral resource availability, in a summerflowering. Mediterranean shrub. Oikos 58:277-288

Höfte H, Whiteley HR (1989) Insecticidal crystal proteins of Bacillus Thuringiensis. Microbiol Rev 53:242-255

Klein AM, Vaissière BE, Cane JH, Steffan-Dewenter I, Cunningham SA, Kremen C, Tscharntke T (2007) Importance of pollinators in changing landscapes for world crops. Proc R Soc Lond B274(1608):303-313

Lambin M, Armengaud C, Raymond S, Gauthier M (2001) Imidacloprid-induced facilitation of the proboscis extension reflex habituation in the honeybee. Arch Insect Biochem 48:129-134

Liu B, Shu C, Xue K, Zhou KX, Li XG, Liu DD, Zheng YP, Xu CR (2009) The oral toxicity of the transgenic $\mathrm{Bt}+\mathrm{CpTI}$ cotton pollen to honey bees (Apis mellifera). Ecotox Environ Safe 72:1163-1169

Lovei GL, Arpaia S (2005) The impact of transgenic plants on natural enemies: a critical review of laboratory studies. Entomol Exp Appl 114:1-14

Malone LA, Pham-Delègue MH (2001) Effects of transgene products on honey bees (Apis mellifera) and bumblebees (Bombus sp.). Apidologie 32:287-304

Masson C, Arnold G (1984) Ontogeny, maturatioen and plasticity of the olfactory system in the worker bee. J. Insect Physiol 30:7-14

Masson C, Pham-Delègue MH, Fonta C, Gascuel J, Arnold G, Nicolas G, Kerszberg M (1993) Recent advances in the concept of adaptation to natural odor signals in the honeybee, Apis mellifera L. Apidologie 24:169-194

Menzel R (1993) Associative learning in honey bees. Apidologie 24:157-168

Mommaerts V, Reynders S, Boulet J, Besard L, Sterk G, Smagghe G (2010) Risk assessment for side-effects of neonicotinoids against bumblebees with and without impairing foraging behaviour. Ecotoxicology 19:207-215

Oldroyd BP (2007) What's killing American honey bees? PLoS Biology 5:1195-1199

Pain J (1966) Nouveau modèle de cagettes expérimentales pour le maintien d'abeilles en captivité. Ann Abeille 9:71-76

Pham-Delègue MH, Bailez O, Blight MM, Masson C, Picard-Nizou AL, Wadhams LJ (1993) Behavioral discrimination of oilseed rape volatiles by the honeybee Apis mellifera $\mathrm{L}$. Chem Senses $18: 483-494$
Pham-Delègue MH, Girard C, Le Metayer M, Picard-Nizou AL, Hennequet C, Pons O, Jouanin L (2000) Long-term effects of soybean protease inhibitors on digestive enzymes, survival and learning abilities of honeybees. Entomol Exp Appl 95:21-29

Picard-Nizou AL, Olsen L, Pioche C, Arnold G, Pham-Delègue MH (1997) Impact of proteins used in plant genetic engineering: toxicity and behavioural study in the honeybee. J Econ Entomol 90:1710-1716

Ramirez-Romero R, Josette C, Pham-Delègue MH (2005) Effects of $\mathrm{Cry} 1 \mathrm{Ab}$ protoxin, deltamethrin and imidacloprid on the foraging activity and the learning performances of the honeybee Apis mellifera, a comparative approach. Apidologie 36:601-611

Ramirez-Romero R, Desneux N, Decourtye A, Chaffiol A, PhamDelègue $\mathrm{MH}$ (2008) Does Cry1Ab protein affect learning performance of the honey bee Apis mellifera L. (Hymenoptera, Apidae)? Ecotox Environ Safe 70:327-333

Romeis J, Bartsch D, Bigler F et al (2008) Assessment of risk of insect-resistant transgenic crops to non-target arthropods. Nat Biotechnol 26:203-208

Seeley TD (1983) Division of labour between scouts and recruits in honeybee foraging. Behav Ecol Sociobiol 11:287-293

Seeley TD (1985) Honeybee ecology. Princeton University Press, Princeton, p 201

Srinivasan MV (2010) Honey bees as a model for vision, perception, and cognition. Annu Rev Entomol 55:267-284

Stokstad E (2007) The case of the empty hives. Science 316:970-972

Stone R (2008) China plans $\$ 3.5$ billion GM crops initiative. Science $321: 1279$

vanEngelsdorp D, Meixner MD (2010) A historical review of managed honey bee populations in Europe and the United States and the factors that may affect them. J Invertebr Pathol 103:S80-S95

Von Frisch K (1915) Der Farbensinn und Formensinn der Biene. Zool Jb Physiol 35:1-188

Yang EC, Chuang YC, Chen YL, Chang LH (2008) Abnormal foraging behavior induced by sublethal dosage of imidacloprid in the honey bee (Hymenoptera: Apidae). J Econ Entomol 101: $1743-1748$

Zhang SW, Bartsch K, Srinivasan MV (1996) Maze learning by honeybees. Neurobiol Learn Mem 66:267-282

Zhang SW, Mizutani A, Srinivasan MV (2000) Maze navigation by honeybees: learning path regularity. Learn Mem 7:363-374 